\title{
Geomicrobial ecotoxicology as a new subject in environmental sciences is proposed
}

\author{
Ji-Dong Gu • Yanxin Wang
}

Accepted: 23 September 2014/Published online: 14 November 2014

(C) Springer Science+Business Media New York 2014

\begin{abstract}
Environmental sciences is an interdisciplinary subject and current development allows investigation of environmental issues from physical, chemical, geological, biological and toxicological approaches. Based on such development, geomicrobial ecotoxicology or microbial ecotoxicology is proposed to advance the information gathering on ecosystem processes and function because microorganisms are numerous and fundamental to the cycling of nutrients and energy flow.
\end{abstract}

Keywords Environmental sciences · Ecotoxicology . Geomicrobial ecotoxicology · Microbial ecotoxicology

The currently known environmental pollution problems are apparently a direct result of increasing exploitation and consumption of natural resources by the increasing population coupling with elevation of living standards worldwide. A much greater pressure on natural ecosystem function, specifically biological processes and the capacities in both intensity and quantity, to the ability by nature in recycling elements/materials can hardly be met under the current conditions. Examples are evident from extraction of petroleum, minerals, and metals and metalloids as well as generation of wastewater and deforestation. All these processes in their natural state involve complex microbial

\section{J.-D. Gu ( $\square)$}

School of Biological Sciences, The University of Hong Kong, Pokfulam Road, Hong Kong, SAR, People's Republic of China e-mail: jdgu@hku.hk

\section{Y. Wang}

State Key Laboratory of Biogeology and Environmental Geology \& School of Environmental Studies, China University of Geosciences, Wuhan 430074, People's Republic of China e-mail: yx.wang@cug.edu.cn community and its function to deal with material transformation in a balanced way, but the human-driven and influenced processes send a feedback negatively to the physical ecosystem, the biological and ecophysiological processes, and eventually the human population with significant evidences. Air becomes polluted, water eutrophified and soils contaminated and drinking water unsafe for consumption by humans and animals. A more depressing picture than those in the Silent Spring seems to be a reality to today's society.

The First International Conference on Geomicrobial Ecotoxicology was held in Wuhan, P.R. China on May 30June 2, 2011 to provide an international forum to discuss a multi-disciplinary subject-geomicrobial ecotoxicology, for the first time, through identified research topics to advance knowledge in geomicrobiology, molecular biology, microbial ecology, biogeochemistry and ecotoxicology of soil, sediment and groundwater systems, and, in particular, the interactions among the difference research subject areas were emphasized. The conference was well attended by 160 participants from 5 countries, including United States, France, United Kingdom, Slovenia and the hosting country P.R. China with 146 contributed abstracts and proceeding papers. Selected manuscripts from presentations at the conference were edited for this Special Issue on Geobiochemical Processes and Ecotoxicology to document and discuss the emerging research field geomicrobial ecotoxicology actively at this conference and also provide a basis for the great potential for this new field to growth and develop in the current and future research.

This collection of 30 selected papers in this Special Issue were among those presented at this conference and was a result of an informal discussion between the two guest editors. We were informally discussing the future about the traditional subject soil microbiology and comparing it to the 
current microbial ecology, and environmental microbiology, particularly in terms of the new research development and creation of new subject areas, and at the same time phasing out of some. We both feel strongly that a new subject on microbial ecotoxicology or geomicrobial ecotoxicology should be distinguished and taught to our environmental sciences students to allow them to better understand environmental issues in a more comprehensive manner to appreciate the complexity of the subject matter and be able to link the microbiology in natural and polluted niches with the ecotoxicological effects and geochemistry knowledge. The reasons are several. Environmental microbiology is at a crossroad to incorporate new or available information to make it more relevant to the physical ecosystem and to deal with matter more comprehensively. Since microorganisms are small and can replicate much quickly, a rapid response to environmental changes can be envisioned and investigated at multiple level for a better understanding of the biochemical, ecophysiological, ecotoxicological and chemical and physical processes involved. Because of the microscopic in nature, investigations on genome, proteomic and expression levels of microorganisms are all possible using available techniques now. Microorganisms can serve as very good and reliable indicators for environmental changes in both research and applications. Such ecophysiological function of unicellular microorganisms offer a great advantage over complex organisms and cells traditionally used in toxicology, environmental toxicology, and ecotoxicology. By using microorganisms, more comparable results can be obtained on a much wide range of research laboratories because the same strains can be used on a global basis and the information from such endeavor will advance the fundamental understanding of research and knowledge on ecotoxicology and environmental toxicology better. Based on this discussion between us, a conference was conceptualized to provide a platform for further discussion and the positive responses from research scientists made it possible to hold the conference and also resulted in two companion special issues, one published previously in International Biodeterioration \& Biodegradation ( $\mathrm{Gu}$ and Wang 2013a, b) and the other is here.

In This Special Issue contains a total of 30 research papers, stress responses in different organisms and toxicity are presented with earth worms (Eisenia fetida), zebra fish (Danio rerio), waterflea (Daphnia magna), and soil microorganisms as receivers while the imposing factors includes chemicals (triclosan, $\mathrm{HgCl}_{2}$, perchlorate, butyl benzyl phthalate, and Chlorpyrifos) and also UV-B in a group of 8 papers. Another 7 papers looks into microbial interactions with metals and metalloids, arsenic is singled out in 5 of the 7 papers in this group to illustrate the global environmental problem with this element and its significance to human life on a polluted planet. On sources and distribution of contaminants, 3 papers on hydrocarbons and arsenic are included here. With the increasing impact by pollution, bioremediation is an increasingly researched subject area and 4 papers feature new data with agricultural crops and also trees to achieve removal of pollutants from contaminated soils or simulated laboratory systems. New assessment techniques are also part of the scientific innovation and provide vital momentum to new and further indepth research, 3 papers on antibiotic determination and isotopic analysis of $\mathrm{S}$ and $\mathrm{N}$ on further understanding the geochemical processes are included in this group. Finally, back to our initial initiative on Microbial Ecotoxicology, 6 papers here show new information of different approaches to analyze the microbial community and responses to anthropogenic pressure. They ranged from microbial community analysis using molecular DNA technique, high through put pyrosequencing, microcalorimetry, association with arbuscular mycorrhizae, and soil enzymes in river sediment from the Pearl River in Southern China, a pristine wetland in the Far East of China, a polluted wetland in an oil city Daqing in Northern China, and also the Loess Plateau of China.

It is our genuine believe and also hope that environmental research can embrace more and more from techniques available from other disciplines, e.g., ecotoxicology and environmental toxicology and molecular toxicology to name a few. At the same time, research should be encouraged to focus on both laboratory conditions and the in situ chemical and biochemical processes of natural ecosystem equipped with the current analytical and molecular biological techniques available to advance our understanding on the processes and the responsive microorganisms involved in their natural state. By doing in this way, an in-depth knowledge of the various processes relevant to ecosystem function can be acquired effectively and the effects of anthropogenic factors on them will be elucidated to advance our knowledge about the microorganisms involved and their responses to the changing ecosystem as anthropogenic impact is continuously to increase (Gu and Wang 2013b; Li et al. 2013).

Environmental pollution and damage by anthropogenic processes are real problems to our long-term survival and sustainability (Gu and Wang 2012). Only based on further collection of new knowledge and technological innovation, will it be possible to deal with the environmental issues facing our society and humanities today, no matter persistent organic chemicals or toxic metals and metalloids (Cheung and $\mathrm{Gu}$ 2007), common pollutant and reactive inorganic nitrogen (Cao et al. 2012, 2013), or endocrinedisrupting chemicals (Gu and Wang 2013b). Without a thorough understanding on the ecotoxicological effects and consequences, intervention to pollution may be achieved through alteration of the biological processes through 
better understanding on the issues involved, mechanisms and strategies (Shao et al. 2013). As a result, any action taken by the government will not be likely environmentally friendly unless information from the various relevant subject areas mentioned above is conducted and available to the public. Because of this, integrated study of environmental issues is urgently needed by fully capitalizing the technology and techniques available to better understand the geochemical, microbiological, geochemical and ecotoxicological processes of the Earth system.

\section{References}

Cao H, Hong Y, Li M, Gu J-D (2012) Community shift of ammoniaoxidizing bacteria along an anthropogenic pollution gradient from the Pearl River Delta to the South China Sea. Appl Microbiol Biotechnol 94:247-259
Cao H, Auguet J-C, Gu J-D (2013) Global ecological pattern of ammonia-oxidizing archaea. PLoS One 8:e52853

Cheung KH, Gu J-D (2007) Mechanisms of hexavalent chromium detoxification by bacteria and bioremediation applications. Int Biodeterior Biodegradation 59:8-15

Gu J-D, Wang Y (2012) Environmental feedback: lessons from pollution problems in China. Ecotoxicology 21:1583-1584

Gu J-D, Wang Y (2013a) A new era for geomicrobial ecotoxicology in environmental science research. Int Biodeterior Biodegradation 85:345-346

$\mathrm{Gu}$ J-D, Wang Y (2013b) Microbial transformation of phthalate esters: diversity of hydrolytic esterases. In: Wong MH (ed) Environmental Contamination-Health Risks. Bioavailability and Bioremediation. CRC Press, Boca Raton, pp 313-345

Li M, Cao H, Hong Y, Gu J-D (2013) Using the variation of anammox bacteria community structures as a bio-indicator for anthropogenic/terrestrial nitrogen inputs in the Pearl River Delta (PRD). Appl Microbiol Biotechnol 97(22):9875-9883

Shao J, Li R, Lepo JE, Gu J-D (2013) Potential for control of cyanobacterial blooms using bioactive substances: problems and prospects. J Environ Manage 125:149-155 